\title{
Effects of Photosensitization of Curcumin in Human Glioblastoma Multiforme Cells
}

\author{
ALEKSANDER KIELBIK ${ }^{1}$, PIOTR WAWRYKA ${ }^{1}$, DAWID PRZYSTUPSKI ${ }^{1}$, JOANNA ROSSOWSKA ${ }^{2}$, \\ ANNA SZEWCZYK ${ }^{3,4}$, JOLANTA SACZKO ${ }^{3}$, JULITA KULBACKA ${ }^{3}$ and AGNIESZKA CHWIŁKOWSKA ${ }^{3}$ \\ ${ }^{1}$ Faculty of Medicine, Wroclaw Medical University, Wroclaw, Poland; \\ ${ }^{2}$ Institute of Immunology and Experimental Therapy Polish Academy of Sciences, Wroclaw, Poland; \\ ${ }^{3}$ Department of Molecular and Cellular Biology, Wroclaw Medical University, Wroclaw, Poland; \\ ${ }^{4}$ Department of Animal Developmental Biology, Institute of Experimental Biology, \\ University of Wroclaw, Wroclaw, Poland
}

\begin{abstract}
Background/Aim: There is no satisfactory treatment of glioblastoma multiforme, a highly invasive brain tumor. The aim of this study was to analyze the cytotoxic effects of curcumin (CUR) alone and as a photosensitizer on glioblastoma cells. Materials and Methods: The SNB-19 cells where incubated for 2 and $24 \mathrm{~h}$ with 5-200 $\mathrm{mM}$ of CUR. The cells were radiated with blue light $\left(6 \mathrm{~J} / \mathrm{cm}^{2}\right)$ and compared to non-irradiated ones. The effects of treatment were assessed by measuring mitochondrial activity with the MTT method and apoptosis progression by flow cytometry. To investigate CUR uptake, fluorescence imaging of cells was performed. Results: Photosensitization of CUR decreased the $E C_{50} 6.3$ times when the incubation time was $2 \mathrm{~h}$ and over $90 \%$ of cells underwent apoptosis. The study of the uptake of CUR showed that during the $2 h, C U R$ was placed in the entire cytoplasm, and over time, its amount decreased and localized in the subcellular compartments. Conclusion: CUR is a promising medicament that can be used as a photosensitizer in photodynamic therapy for glioma treatment.
\end{abstract}

Gliomas constitute $74 \%$ of the most mortal forms of malignant brain and central nervous system (CNS) primary tumors. Within this group the most common histology subtype, accounting for $54.7 \%$ of all gliomas, is glioblastoma (1). Glioblastomas are also known to be the most aggressive brain tumors with around 50\% 1-year survival and $10-5 \%$ 5-year

This article is freely accessible online.

Correspondence to: Agnieszka Chwiłkowska, Department of Molecular and Cellular Biology, Wroclaw Medical University, 211A, Borowska Str., 50-556, Wroclaw, Poland. Tel: +48 717840690,e-mail: agnieszka.chwilkowska@umed.wroc.pl

Key Words: Photodynamic reaction, curcumin, glioblastoma, experimental oncology. survival (2). Glioblastoma multiforme (GBM) is the most aggressive of these, graded by WHO as grade 4. Present guidelines recommend the maximal safe resection or, in case when it is not feasible, subtotal resection. Further adjuvant therapy depends on patient's age and performance status, but in all cases brain radiotherapy and concurrent temozolomide therapy are recommended (3). The development of novel and more selective therapies may lead to more effective treatment.

Photodynamic therapy (PDT) is known as a minimally invasive therapeutic procedure. It is largely utilized in the oncological field in multiple specialties. For instance, in dermatology against squamous cell carcinoma in situ (SCC in situ) and basal cell carcinoma (BCC) treatment (4). In head and neck cancers PDT is curatively applicable for early cancer and local recurrences $(5,6)$. Moreover, for lung tumor treatment, PDT is performed bronchoscopically for central-type lung cancer and often for non-small cell lung cancer (7). In the Barrett's esophagus and esophagus cancer, performance of PDT induces elimination of Barrett's mucosa and consequently reduction in the progression to adenocarcinoma (8). Furthermore, PDT shows promising therapeutic effects for cholangiocarcinomas (9), brain tumors (10), and urologic tumors (11).

PDT involves two steps: the topical or systematic application of inactive photosensitizer (PS) and its excitation by irradiation with appropriate wave length light. Triggering of PS causes production of reactive oxygen species (ROS) in two types of reactions: Type 1 - electron transfer reactions and type 2 - energy transfer reactions. Both mechanisms take place simultaneously and are dependent on multiple parameters such as tissue oxygenation and type of PS. Subsequently, ROS can affect the tumor cells directly or indirectly activating the inflammatory response or harming tumor vascularization $(12,13)$.

The effectiveness of PDT depends largely on the type of photosensitizer used. There are several types of PS investigated such as porphyrins, chlorins, bacteriochlorines 
or phthalocyanines, but clinically, for PDT on solid tumors, porphyrin and phthalocyanine derivatives are the most common photosensitizes (14).

The main features which need to be considered when choosing a PS are: the ability to preferentially accumulate in diseased tissue, low dark toxicity, negligible cytotoxicity in the absence of light and rapid clearance from the body after the procedure (15).

Continuous and rapid development of treatment strategies creates the need of searching for new PS agents also among natural substances.

One of the substances that, apart from its anti-cancer effect, can be used as a photosensitizer is curcumin (CUR). CUR is the principal curcuminoid of turmeric - a member of the ginger family. Pure turmeric powder has the highest CUR concentration, on average $3.14 \%$ by weight (16). It has been shown that CUR possesses anti-inflammatory effects (17), antioxidant effects (18) and hypolipidemic effects (19). The anti-cancer effect of CUR was observed on multiple types of tumors including breast, colon, stomach, liver, lung, prostate, cervical, osteosarcoma and head and neck squamous cell carcinoma (20-24). CUR attributes its anticancer effect to several types of mechanisms.

We postulate that the use of curcumin as a photosensitizer may significantly reduce CUR concentration administered systemically. The aim of the study was to examine whether CUR works more effectively as a photosensitizer and leads to a more efficient elimination of glioblastoma cells in apoptotic manner than CUR applicated as an anticancer drug in vitro.

\section{Materials and Methods}

Cell culture. The SNB-19 glioblastoma cell line derived from a surgical resection of a left parieto-occipital glioblastoma multiforme tumor from a 47-years-old male (25). Cells were grown in monolayer cultures in Dulbecco's modified Eagle's medium (DMEM, Sigma-Aldrich, St. Louis, MO, USA) supplemented with $10 \%$ fetal bovine serum (FBS, Sigma-Aldrich) and antibiotics (penicillin/streptomycin; Sigma-Aldrich) under standard culture conditions at $37^{\circ} \mathrm{C}$ in a humidified atmosphere containing $5 \% \mathrm{CO}_{2}$. When needed, the cells were rinsed with PBS and removed by trypsinization ( $0.025 \%$ trypsin and $0.02 \%$ EDTA; Sigma-Aldrich).

Preparation of drug. The curcumin (1E, 6E)-1,7-bis (4-hydroxy- 3methoxyphenyl) -1,6- heptadiene-3,5-dione (Sigma-Aldrich) was dissolved in dimethyl sulfoxide (DMSO, Sigma-Aldrich) to prepare $1 \mathrm{mM}$ stock of CUR. Stock of CUR was freshly prepared before every experiment. Subsequently the proper amount of stock was mixed with DMEM to achieve the required concentration of the drug. DMSO content in the working solution was less than $4 \%$, which could not affect the course of the experiment.

The photodynamic reaction triggering. The photodynamic reaction was performed by a lamp with polarized light (Optel, Poland). The radiation power density was $6 \mathrm{~J} / \mathrm{cm}^{2}$. The blue light was used to perform the photodynamic reaction with CUR on SNB-19 cells, since the light absorption peak of CUR is $410 \mathrm{~nm}$. The irradiance homogeneity over the plate area was proved using a radiometer (MRT-06, Optel, Poland).

Curcumin treatment with and without irradiation - study in vitro, Cells were seeded in 96-well plates in count of $1 \times 10^{4}$ cells per well and incubated overnight in complete growth medium to allow for cell attachment. Then DMEM was replaced with media containing different concentrations $(0,5,10,15,25,50,100,200 \mathrm{mM})$ of CUR and subsequently the plates were further incubated in the dark for 2 and $24 \mathrm{~h}$. After this incubation, cell culture medium was replaced with fresh DMEM before irradiation. Then cells were incubated for $24 \mathrm{~h}$ and cell viability measurements were carried out afterwards.

Cell viability measurement. Cell viability was measured using the MTT assay, a method based on the activity of mitochondrial dehydrogenases. Culture medium was removed from the wells and $100 \mu \mathrm{l}$ of $0.5 \mathrm{mg} / \mathrm{ml}$ MTT (3-(4,5-dimethylthiazol-2-yl)-2,5-diphenyltetrazolium bromide, Sigma) in PBS buffer was added. After $2 \mathrm{~h}$ incubation at $37^{\circ} \mathrm{C} 100 \mu \mathrm{l}$ of the acidified isopropanol ( $0.04 \mathrm{M} \mathrm{HCl}$ in absolute isopropanol) was added to dissolve formazan crystals. Absorbance was measured at 570 $\mathrm{nm}$ using the multiplate reader (EnSpire, Perkin Elmer, Waltham, MA, USA). The results were expressed as the percentage of viable cells relative to untreated control cells.

Cell death quantification assay. The SNB-19 cells were placed on 6-well plates and allowed to attach. Then the cells were incubated for 2 and $24 \mathrm{~h}$ in 10 and $50 \mu \mathrm{M}$ CUR solution. The cells were irradiated to determine the effect of photodynamic reaction with CUR or not to evaluate the action of CUR alone on cell death. Subsequently, the medium was replaced with DMEM and the cells were incubated for $24 \mathrm{~h}$, washed with PBS and trypsinized. The cells were stained with fluorochrome-labeled Annexin V which was used to detect phosphatidylserine (PS) exposure on the cell surface in the early stage of apoptosis, and also stained with propidium iodide (PI) to detect of secondary necrotic cells related with loss of plasma membrane integrity according to the manufacturer's instructions (APC Apoptosis Kit with PI, BioLegend San Diego, CA, USA). Fluorescent intensities were determined on FACS Calibur flow cytometer (Becton Dickinson, Biosciences, San Jose, CA, USA).

Confocal laser microscopy study. To analyze CUR uptake and visualize the cell morphology a confocal laser scanning microscopy (CLMS) was used. The SNB-19 cells were incubated on cover glasses in Petri dishes overnight and then treated for 2 and $24 \mathrm{~h}$ with $10 \mu \mathrm{M}$ CUR. After incubation the cells were washed 3 times with PBS and DAPI (4,6-diamidino-2-phenylindole; $0.2 \mu \mathrm{g} / \mathrm{ml}$, ex/em. 358/461 nm) was applied to visualize nuclear DNA. At the end, cells were treated with mounting medium (DAKO, Gdynia, Poland). The cells were observed in Olympus FluoView FV1000 confocal laser scanning microscope (Olympus, Tokyo, Japan). Plan-Apochromat $60 \times$ oilimmersion objective was used to capture the images.

Statistical analysis. The effect of every concentration of CUR (with and without irradiation) was examined on 5 or 4 wells. The experiments were performed in 3 replicates. Data are expressed as mean \pm standard deviation of the mean and were analyzed by twoway ANOVA (in GraphPad Prism 7), with $p<0.05$ being considered statistically significant. $\mathrm{EC}_{50}$ values were calculated by nonlinear regression (curve fit) of cytotoxicity data using sigmoidal dose response (variable slope) equation. 

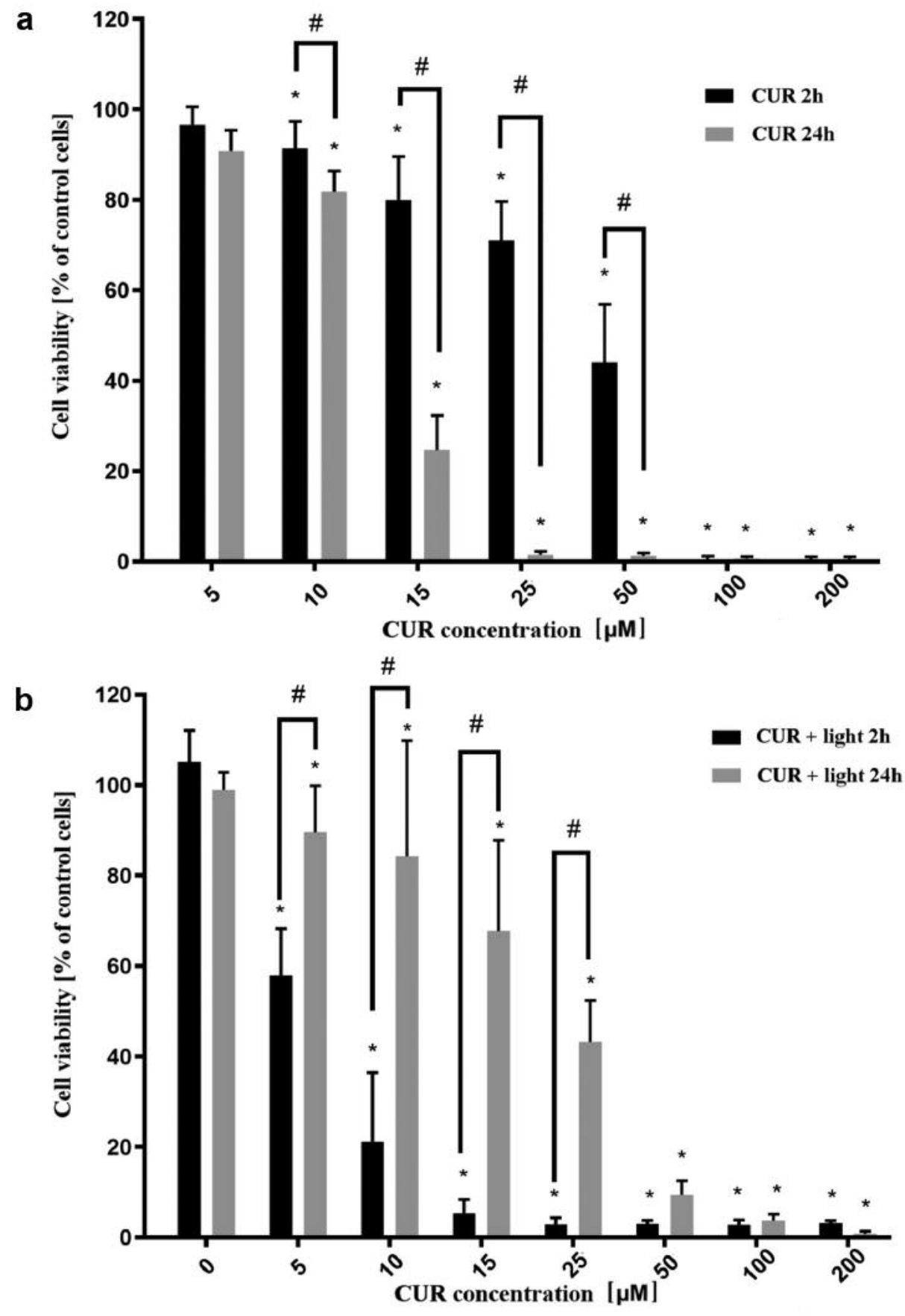

Figure 1. Viability of SNB-19 cells measured by the MTT assay a) after 2 and $24 \mathrm{~h}$ incubation in different CUR concentrations, $b)$ after photodynamic reaction, following 2 and 24 h incubation in different CUR concentrations. Notes: (mean $\pm S D) N=5 \times 3, * p<0.05$ compared to control, ${ }^{*} p<0.05$ compared between different incubation times.

\section{Results}

Cell viability measured by the MTT assay. The incubation with CUR significantly decreased cell viability in comparison to control (Figure 1a). Lower viability of tumor cells was observed after $24 \mathrm{~h}$ incubation, and was especially visible in CUR concentrations from 15 to $50 \mathrm{mM}$. The application of photodynamic reaction with CUR as a photosensitizer significantly decreased cancer cell viability after $2 \mathrm{~h}$ incubation compared with the non-irradiated group (Figure 1). 
The photosensitization enabled the use of 6,3 times lower concentration of drug to decrease tumor cells viability by $50 \%$ compared with curcumin therapy without radiation (Table I). The enhancing effect of photodynamic radiation was not observed after longer incubation time (Figure 1, Table I).

Effect of CUR on apoptosis. To monitor the progression of apoptosis, the phenotypic changes occurring in apoptotic cells were analyzed and quantified by double staining of SNB-19 cells with fluorochrome-labeled Annexin V and PI. The study revealed that $2 \mathrm{~h}$ of CUR treatment using the concentrations of 10 and $50 \mu \mathrm{M}$ reduces the percentage of living cells by $25 \%$ and $50 \%$ respectively. Incubation for 24 $\mathrm{h}$ with $10 \mu \mathrm{M}$ CUR for $24 \mathrm{~h}$ resulted in about $65 \%$ dead cells, whereas with $50 \mu \mathrm{M}$ CUR gave nearly $100 \%$ of dead cell (Figure 2). Longer incubation time with CUR resulted in a higher ratio of apoptotic cells (Figure 2a and c), and the application of photodynamic reaction after $2 \mathrm{~h}$ incubation led to over $90 \%$ cell apoptosis (Figure $2 \mathrm{a}$ and $\mathrm{b}$ ). The use of photodynamic reaction after $24 \mathrm{~h}$ of incubation showed an increase in apoptosis at $10 \mu \mathrm{M}$ and a decrease in necrosis at $50 \mu \mathrm{M}$, compared to CUR treatment alone (Figure $2 \mathrm{c}$ and $\mathrm{d}$ ).

The intracellular localization of curcumin. To trace the intracellular localization of CUR after different incubation times, fluorescence emitted by cellular CUR was observed. The green fluorescence emitted by CUR in the cells was visible after $2 \mathrm{~h}$ of incubation and was uniformly distributed over the entire cell (Figure 3). After a 24-h incubation, fluorescence was noticed unevenly placed in the cytoplasm (Figure 3). This suggested that after reaching an optimum in about $2 \mathrm{~h}$, CUR absorbed by cancer cells changes localization and decreases with time.

\section{Discussion}

In this study, responses of glioblastoma cells to curcumin treatment were investigated. The $\mathrm{EC}_{50}$ for glioblastoma cells was calculated to be below $40 \mu \mathrm{M}$. Hande et al. obtained similar values of $\mathrm{IC}_{50}$ for glioblastoma multiforme and medulloblastoma $\left(\mathrm{IC}_{50}<50 \mu \mathrm{M}\right)$ cells in in vitro studies. Additionally, they have shown that healthy human fibroblast cells displayed the highest $\mathrm{IC}_{50}$ of $90 \mu \mathrm{M}$ and were more resistant to CUR than brain tumor cell lines (24). Furthermore, several in vitro studies confirmed the selective effect of CUR on cancer cells. Kunwar et al. have examined the cellular uptake of CUR and noticed that tumor cells showed significantly higher uptake of CUR as compared to normal cells (26). Chang et al. have shown that CUR induced greater cytotoxicity on osteosarcoma cells than on healthy human osteoblasts in a dose-dependent manner (27). Finally, Krishnan et al. have established that CUR after $48 \mathrm{~h}$ incubation showed no significant cytotoxicity on primary
Table I. EC 50 value of CUR as a drug and as a photosensitizer. Results expressed in $\mathrm{mM}$ of $C U R$.

\begin{tabular}{lcrc}
\hline $\begin{array}{l}\text { Time of incubation } \\
{[\mathrm{h}]}\end{array}$ & $\begin{array}{c}\text { CUR } \\
{[\mu \mathrm{M}]}\end{array}$ & $\begin{array}{c}\text { CUR }[\mu \mathrm{M}]+ \\
\text { light }\end{array}$ & $\begin{array}{l}\text { Ratio } \\
\text { (fold) }\end{array}$ \\
\hline 2 & $36.5 \pm 2.0$ & $5.74 \pm 0.21$ & 6.3 \\
24 & $12.8 \pm 2.3$ & $21.60 \pm 1.20$ & 0.6 \\
\hline
\end{tabular}

cortical neurons and astrocytes in up to $50 \mu \mathrm{M}$ concentration (28). The results of these studies indicate that CUR has a selective anticancer effect, but to uncover the mechanism further structural and molecular research on tumor and normal cell lines is required.

The determination of intracellular localization of CUR might be helpful in explaining the anticancer effect of this substance. Since CUR has lipophilic properties it was expected to accumulate mainly in the cell membrane. Kunwar et al. have confirmed the differential uptake of CUR in sub-cellular components (26). The highest percentage of curcumin was observed in the membrane fraction, and then in the order membrane $>$ cytoplasm $>$ nucleus $>$ mitochondria.

In most of the studies carried out both on humans and animals, CUR was delivered orally (29). After oral administration of a $2 \mathrm{~g} / \mathrm{kg}$ dose, in rats, CUR reached the maximum serum concentration of $1.35 \pm 0.23 \mu \mathrm{g} / \mathrm{ml}$. In humans, however, after the same dose, the serum levels of CUR were either undetectable or extremely low $(0.006 \pm 0.005 \mu \mathrm{g} / \mathrm{ml})(29)$. There are four main obstacles in reaching satisfactory concentrations of CUR in the bloodstream: poor solubility in blood due to its lipophilic character, low absorption from the gut, rapid metabolism and rapid systemic elimination (30).

Clearly poor solubility in water (about $11 \mathrm{ng} / \mathrm{ml}$ ), limits its absorption from the gut (31). To overcome this problem scientists suggested some solutions such as: 1) binding of CUR to a carrier to facilitate its transportation from the gut to the bloodstream, 2) addition of inhibitors of the common phase II enzymes to slow down the metabolism of CUR and eventually 3) synthesis of analogs or conjugates to not only improve poor solubility, but also stability of the compound. Some trials included also combinations of the abovementioned techniques (32).

A promising strategy, based on self-microemulsifying drug delivery systems (SMEDDS), has been described by Saipin et al. (33). Application of this suspensions showed 14- and 10 - fold increased absorption in comparison with aqueous suspensions of CUR (31).

Another compelling alternative seems to be additional use of piperine, a natural alkaloid that has been described to inhibit glucuronidation in both rodents and humans. The effectiveness of this approach was tested on human volunteers who after administration of $25 \mathrm{mg}$ of piperine and 


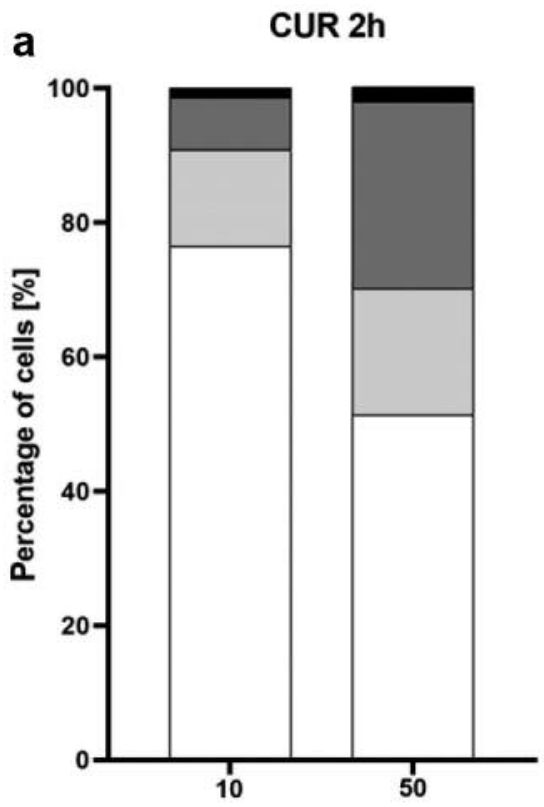

Concentration of CUR $[\mu \mathrm{M}]$

b CUR 2h PDT

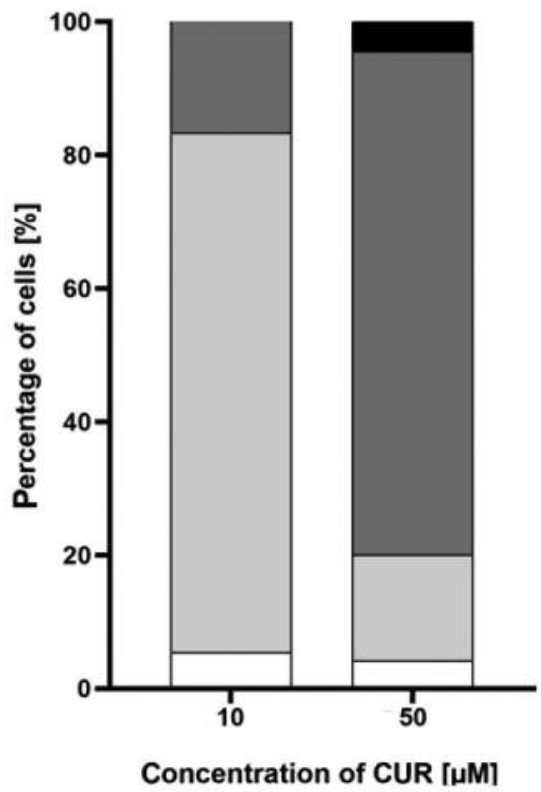

C

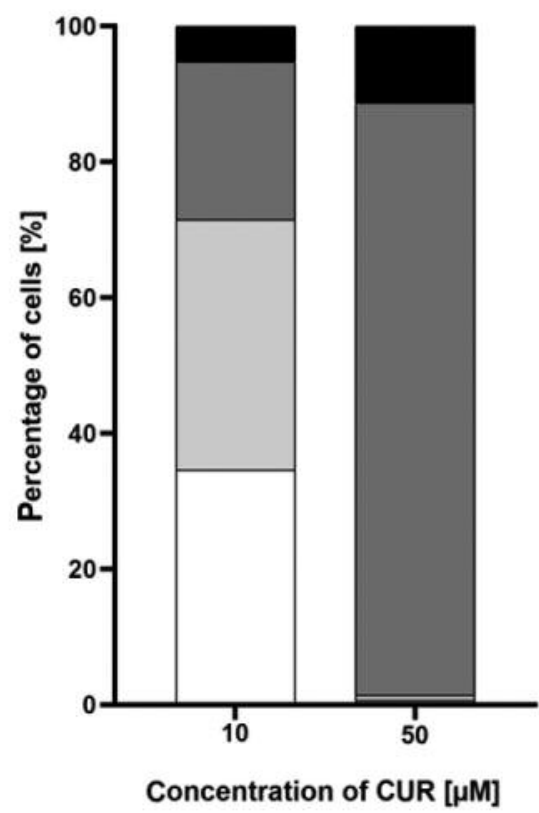

d
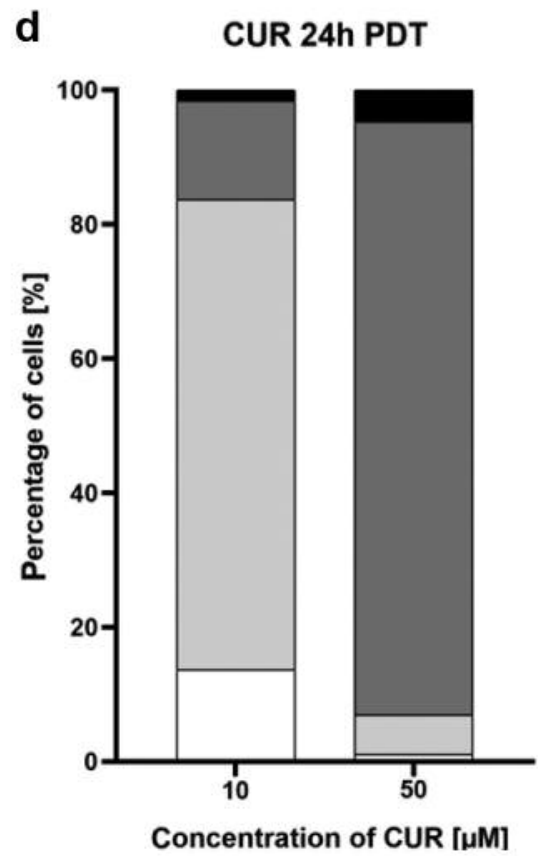

Figure 2. The percentage ratio of undamaged, necrotic, apoptotic and late apoptotic SNB-19 cells after different times of incubation with CUR (a, c) and incubation with CUR followed by photodynamic reaction $(b, d)$. Results expressed as percentage of cells.

$2 \mathrm{~g}$ of CUR developed CMAX of $0.08 \pm 0.01 \mu \mathrm{g} / \mathrm{ml}(32)$. Additionally, the study of Ryu et al. has shown, that usage of piperine increased CUR brain uptake by $48 \%$ compared to the same dose of CUR without piperine. The uptake from other organs remained nearly the same (34).
An interesting approach that enhanced CUR bioavailability was presented in the study of Purpura et al. They measured the bioavailability of $\gamma$-cyclodextrin CUR formulation (CW8). CW8 gave a 39.1-fold increase in relative bioavailability of CUR in comparison with standardized unformulated CUR extract (35). 
Oral administration maybe well described and studied, but intravenous injections of CUR appear to result in higher concentrations of the drug in serum. Studies have shown that $10 \mathrm{mg} / \mathrm{kg}$ of CUR injected intravenously in rats gave a maximum serum CUR level of $0.36 \mu \mathrm{g} / \mathrm{ml}$ (in comparison, a 50 -fold higher CUR dose given orally resulted only in $0.06 \pm 0.01 \mu \mathrm{g} / \mathrm{ml}$ maximum serum level) (29). There are several studies where scientists attempted to increase bioavailability of CUR after intravenous administration. They included Inulin- $d-\alpha$-Tocopherol Succinate (INVITE) nanomicelles (36) or used Redox nanoparticles to inhibit CUR oxidative degradation (37).

The most perspective method is linking CUR with glioblastoma specific antibodies - CD68. Using this technique Langone et al. have reached 120 -fold decrease in the $\mathrm{IC}_{50}$ of CUR on different glioblastoma cell lines. Moreover, the applied amount of CUR had no significant effect on healthy cells. In vivo studies on mice with the CUR-linked antibodies provided 1.5 $\mu \mathrm{M}$ CUR concentration in the tumor tissue (38).

Therefore, taking into account the studies discussed above, intravenous administration of CUR seems reasonable in glioblastoma therapy. Nevertheless, more studies are required to enhance CUR concentration in tumor site and to establish more effective curcumin treatment methods. In our study, we proposed another way of improvement of CUR's function. To increase the efficiency of curcumin treatment, we investigated the effect of photodynamic reaction with CUR on the viability of glioblastoma cells. We observed a 6.3 -fold decrease in the $\mathrm{EC}_{50}$ after photoactivation of CUR following $2 \mathrm{~h}$ incubation. However, radiation of cancer cells after $24 \mathrm{~h}$ incubation showed no additional effect emphasizing the importance of a short incubation time. The study of apoptosis confirmed the increase in the effectiveness of CUR therapy after the application of the photodynamic reaction. Cell death occurred almost entirely via apoptosis. Investigation of the localization of CUR provided a possible explanation for this phenomenon; high CUR fluorescence was observed after $2 \mathrm{~h}$. Kunwar et al. have shown that after $0.5 \mathrm{~h}$ fluorescence, CUR in MCF7 cells was observed in the entire cell, and over time the fluorescence intensity appeared to be localized in various compartments (26). The change in CUR localization with time may result in increased cell survival after $24 \mathrm{~h}$ of incubation and application of photodynamic reaction.

The current study indicated, that this relatively short time might provide the best safety and convenience of therapy in future trials and photosensitization of curcumin decreases the dose which has to be achieved in serum.

Jamali et al. have broached the subject of PDT with CUR as a photosensitizer on brain tumor cells. They performed the photodynamic reaction (blue LEDs, radiation dose light 60 $\mathrm{J} / \mathrm{cm} 2$ ) with CUR as photosensitizer on the DKMG cell line. Results showed significant and promising CUR dosedependent reduction in cell viability (39). The outcome

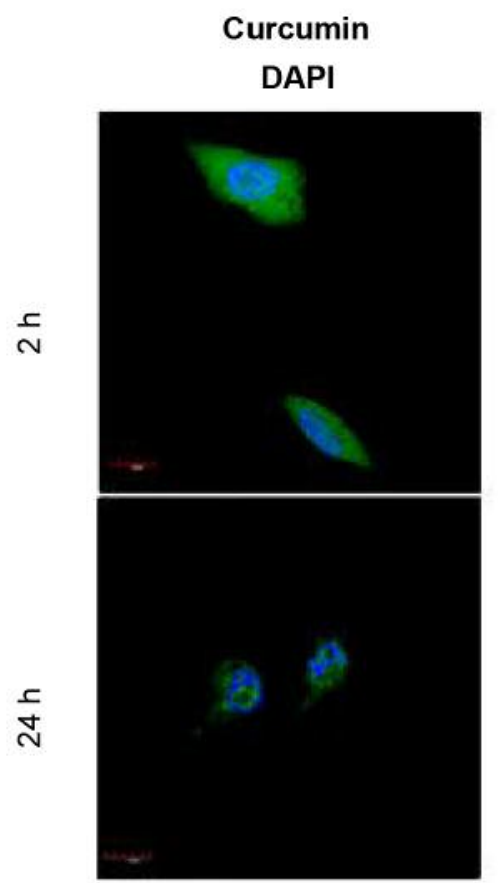

Figure 3. Intracellular localization of CUR in SNB-19 cells. The FITC filter was used to detect fluorescence emitted by CUR. DAPI filter was used to achieve DNA selective fluorescence.

obtained by Jamali et al. is compatible with the results of our trials. Although the use of CUR as a photosensitizer has not been tested in any clinical trial, there are numerous other studies investigating the in vitro effect of CUR in PDT on multiple cancer cells i.e. oral cancer cells (40), cervical carcinoma cells (41) as well as human keratinocyte (42), colon and prostate cancer (43). According to the latest reports, CUR induces apoptosis by involving several mechanisms: 1) upregulation of p53 expression, 2) increased Bax expression, that leads to initiation of mitochondrial apoptotic pathway, and 3 ) expression and release of cytochrome c (23). Taken together, our results indicated that CUR is a promising medicament and PTD photosensitizer for brain cancer. Although a 2-h incubation time seemed to be optimal to achieve the best outcome, the actual delay time between drug administration and radiation in vivo requires further investigations.

Even though there are no recommendations to use photodynamic therapy as an adjuvant therapy for glioblastoma, some clinical studies have shown promising results. In these studies, talaporfin sodium was administrated intravenously as a photosensitizer and the resection cavity was irradiated using 664-nm semiconductor laser. The analysis of treatment efficiency was mainly focused on newly diagnosed or recurrent GBM. Due to strict criteria and the fact that brain tumors are relatively rare in the population, the number of study participants wasn't high 
enough to clearly confirm the effectiveness of adjuvant PDT. However, considering the results, the physicians concluded that PDT may provide an additional benefit to the treatment of primary malignant high-grade brain tumors and it may lead to prolongation of patient's survival. Moreover, PDT is safe and provides minimal risk of side-effects, so future studies may safely analyze a high number of patients (44).

\section{Conflicts of Interest}

The Authors declare that they have no competing interests in regard to this study.

\section{Authors' Contributions}

Conceptualization: AK, PW, JK; experiment performance: AK, PW, DP, JR, AS; writing - original draft preparation: AK, PW; writing - review and editing: AC; funding acquisition: JS, JK, supervision: JK, AC.

\section{Acknowledgements}

The work was performed as part of the activity of the Student Research Group "Biology of Cancer Cell" at the Wroclaw Medical University (SKN No. K 148) and Statutory Funds of Department of Molecular and Cellular Biology. The publication was prepared under the project financed from the funds granted by the Ministry of Science and Higher Education in the "Regional Initiative of Excellence" programme for the years 2019-2022, project number 016/RID/2018/19, with the amount of funding 11,998,121.30 PLN

\section{References}

1 Ostrom QT, Gittleman H, Liao P, Rouse C, Chen Y, Dowling J, Wolinsky Y, Kruchko $\mathrm{C}$ and Barnholtz-Sloan J: CBTRUS statistical report: Primary brain and central nervous system tumors diagnosed in the United States in 2007-2011. Neuro Oncol 16: iv1-iv63, 2014. PMID: 25304271. DOI: 10.1093/ neuonc/nou223

2 Grossman SA, Ye X, Piantadosi S, Desideri S, Nabors LB, Rosenfeld $\mathrm{M}$ and Fisher J: Survival of patients with newly diagnosed glioblastoma treated with radiation and temozolomide on research studies in the United States. Clin Cancer Res 16(8): 2443-2449, 2010. PMID: 20371685. DOI: 10.1158/10780432.CCR-09-3106

3 Nabors LB, Portnow J, Ammirati M, Brem H, Brown P, Butowski N, Chamberlain MC, Deangelis LM, Fenstermaker RA, Friedman A, Gilbert MR, Hattangadi-gluth J, Hesser D, Holdhoff M, Junck L, Lawson R, Loeffler JS, Moots PL, Mrugala MM, Newton HB, Raizer JJ, Recht L, Shonka N, Shrieve DC, Sills AK Jr., Swinnen LJ, Tran D, Tran N, Vrionis FD, Wen PY, McMillian NR and Ho M: Central nervous system cancers, featured updates to the NCCN Guidelines. J Natl Compr Cancer Netw 12(11): 1517-1523, 2014. PMID: 25361798. DOI: $10.1007 / \mathrm{s} 00330-006-0435-7$

4 Morton C: The emerging role of 5-ALA-PDT in dermatology: is PDT superior to standard treatments? J Dermatolog Treat 13: 2529, 2002. PMID: 12060514. DOI: 10.1080/0954663 02317414672

5 Von Beckerath MP, Reizenstein JA, Berner AL, Nordqvist KWO, Landström FJ, Löfgren AL and Möller CG: Outcome of primary treatment of early laryngeal malignancies using photodynamic therapy. Acta Otolaryngol 134(8): 852-858, 2014. PMID: 24856450. DOI: 10.3109/00016489.2014.906748

6 Green B, Cobb ARM and Hopper C: Photodynamic therapy in the management of lesions of the head and neck. Br J Oral Maxillofac Surg 51(4): 283-287, 2013. PMID: 23245464. DOI: 10.1016/j.bjoms.2012.11.011

7 Kimura M, Miyajima K, Kojika M, Kono $\mathrm{T}$ and Kato $\mathrm{H}$ : Photodynamic therapy (PDT) with chemotherapy for advanced lung cancer with airway stenosis. Int J Mol Sci 16(10): 2546625475, 2015. PMID: 26512656. DOI: 10.3390/ijms 161025466

8 Moghissi K, Dixon K, Thorpe JAC, Stringer M and Moore PJ: The role of photodynamic therapy (PDT) in inoperable oesophageal cancer. Eur J Cardio-thoracic Surg 17(2): 95-100, 2000. PMID: 23245464. DOI: 10.1016/S1010-7940(99)00350-4

9 Moole H, Tathireddy H, Dharmapuri S, Moole V, Boddireddy R, Yedama P, Dharmapuri S, Uppu A, Bondalapati N and Duvvuri A: Success of photodynamic therapy in palliating patients with nonresectable cholangiocarcinoma: A systematic review and meta-analysis. World J Gastroenterol 23(7): 1278-1288, 2017. PMID: 23245464. DOI: 10.3748/wjg.v23.i7.1278

10 Fisher CJ and Lilge L: Photodynamic therapy in the treatment of intracranial gliomas: A review of current practice and considerations for future clinical directions. J Innov Opt Health Sci 08(01): 1530005, 2015. DOI: 10.1142/S1793545815300050

11 Pinthus JH, Bogaards A, Weersink R, Wilson BC and Trachtenberg J: Photodynamic therapy for urological malignancies: Past to current approaches. J Urol 175(4): 1201-1207, 2006. PMID: 16515960. DOI: 10.1016/S0022-5347(05)00701-9

12 Castano AP, Demidova TN and Hamblin MR: Mechanisms in photodynamic therapy: Part two - Cellular signaling, cell metabolism and modes of cell death. Photodiagnosis Photodyn Ther 2: 1-23, 2005. PMID: 25048553. DOI: 10.1016/S15721000(05)00030-X

$13 \mathrm{Li} \mathrm{W}, \mathrm{Ma} \mathrm{Q}$ and Wu E: Perspectives on the role of photodynamic therapy in the treatment of pancreatic cancer. Int J Photoenergy 2012: 637429, 2012. PMID: 28714406. DOI: 10.1155/2012/637429

14 Dąbrowski JM and Arnaut LG: Photodynamic therapy (PDT) of cancer: From local to systemic treatment. Photochem Photobiol Sci 14(10): 1765-1780, 2015. PMID: 26219737. DOI: 10.1039/ c5pp00132c

15 Wilson BC and Patterson MS: The physics, biophysics and technology of photodynamic therapy. Phys Med Biol 53(9): R61109, 2008. PMID: 18401068. DOI: 10.1088/0031-9155/53/9/R01

16 Tayyem RF, Heath DD, Delaimy-Al KW and Rock LC: Curcumin content of turmeric and curry powders. Nutr Cancer 55(2): 126131, 2006. PMID: 17044766. DOI: 10.1207/s1532 7914nc5502_2

17 Heeba GH, Mahmoud ME and Hanafy AAE: Anti-inflammatory potential of curcumin and quercetin in rats: Role of oxidative stress, heme oxygenase-1 and TNF- $\alpha$. Toxicol Ind Health $30(6)$ : 551-560, 2014. PMID: 23024111. DOI: 10.1177/074823371 2462444

18 Haryuna TSH, Munir D, Maria A and Bashiruddin J: The antioxidant effect of curcumin on cochlear fibroblasts in rat models of diabetes mellitus. Iran J Otorhinolaryngol 29(4): 197-202, 2017. PMID: 28819617. DOI: 10.22038/ijorl.2017. 19603.1660

19 Zhong Y, Feng J, Fan Z and Li J: Curcumin increases cholesterol efflux via hemeoxygenase-1-mediated ABCA1 and SR-BI expression in macrophages. Mol Med Rep 17(4): 6138-6143, 2018. PMID: 29436680. DOI: $10.3892 / \mathrm{mmr} .2018 .8577$ 
20 Ramachandran C and You W: Differential sensitivity of human mammary epithelial and breast carcinoma cell lines to curcumin. Breast Cancer Res Treat 54(3): 269-278, 1999. PMID: 10445 426. DOI:10.1023/A:1006170224414

21 Tong W, Wang Q, Sun D and Suo J: Curcumin suppresses colon cancer cell invasion via AMPK-induced inhibition of NF- $x \mathrm{~B}$, uPA activator and MMP9. Oncol Lett 12(5): 4139-4146, 2016. PMID: 27895783. DOI: 10.3892/ol.2016.5148

22 Wei Y and Lee RJ: Liposomal curcumin and its application in cancer Physical property. Int J Nanomedicine 12: 6027-6044, 2017. PMID: 28860764. DOI: $10.2147 /$ IJN.S132434

23 Wilken R, Veena MS, Wang MB and Srivatsan ES: Curcumin: A review of anti-cancer properties and therapeutic activity in head and neck squamous cell carcinoma. Mol Cancer 10: 1-20, 2011. PMID: 21299897. DOI: 10.1186/1476-4598-10-12

24 Hande MP, Khaw AK, Hande MP and Kalthur G: Curcumin inhibits telomerase and induces telomere shortening and apoptosis in brain tumour cells. J Cell Biochem 114(6): 12571270, 2013. PMID: 23192708. DOI: $10.1002 /$ jcb.24466

25 William W, Richard M, Janet G, Golinn S and Kitson R: Morphologic, immunologic, biochemical and cytogenetic characteristic of the human glioblastoma - derived cell line, SNB-19. Vitr Cell Dev Biol-Animal 31(16): 610-616, 1995. PMID: 8528516. DOI: 10.1021/ja00899a017

26 Kunwar A, Barik A, Mishra B, Rathinasamy K, Pandey R and Priyadarsini KI: Quantitative cellular uptake, localization and cytotoxicity of curcumin in normal and tumor cells. Biochim Biophys Acta - Gen Subj 1780(4): 673-679, 2008. PMID: 18178166. DOI: 10.1016/j.bbagen.2007.11.016

27 Chang R, Sun L and Webster TJ: Short communication: Selective cytotoxicity of curcumin on osteosarcoma cells compared to healthy osteoblasts. Int J Nanomedicine 9(1): 461465, 2014. PMID: 24453488. DOI: 10.2147/IJN.S55505

28 Krishnan DM, Mahesh VB and Brann DW: Curcumin suppresses growth and chemoresistance of human glioblastoma cells via AP1 and NF j B transcription factors. J Neurochem 102: 522-538, 2007. PMID: 17596214. DOI: 10.1111/j.1471-4159.2007.04633.x

29 Prasad S, Tyagi AK and Aggarwal BB: Recent developments in delivery, bioavailability, absorption and metabolism of curcumin: The golden pigment from golden spice. Cancer Res Treat 46(1): 2-18, 2014. PMID: 24520218. DOI: 10.4143/crt.2014.46.1.2

30 Jamwal R: Bioavailable curcumin formulations: A review of pharmacokinetic studies in healthy volunteers. J Integr Med 16(6): 367-374, 2018. PMID: 30006023. DOI: 10.1016/j.joim. 2018.07.001

31 Liu W, Zhai Y, Heng X, Che FY, Chen W, Sun D and Zhai G: Oral bioavailability of curcumin: problems and advancements. J Drug Target 24(8): 694-702, 2016. PMID: 26942997. DOI: 10.3109/1061186X.2016.1157883

32 Mahran RI, Hagras MM, Sun D and Brenner DE: Bringing curcumin to the clinic in cancer prevention: a review of strategies to enhance bioavailability and efficacy. AAPS J 19(1): 54-81, 2017. PMID: 27783266. DOI: 10.1208/s12248-016-0003-2

33 Setthacheewakul S, Mahattanadul S, Phadoongsombut N, Pichayakorn W and Wiwattanapatapee R: Development and evaluation of self-microemulsifying liquid and pellet formulations of curcumin, and absorption studies in rats. Eur $\mathbf{J}$ Pharm Biopharm 76(3): 475-485, 2010. PMID: 20659556. DOI: 10.1016/j.ejpb.2010.07.011

34 Ryu EK, Choe YS, Lee KH, Choi Y and Kim BT: Curcumin and dehydrozingerone derivatives: Synthesis, radiolabeling, and evaluation for $\beta$-amyloid plaque imaging. J Med Chem 49(20): 6111-6119, 2006. PMID: 17004725. DOI: 10.1021/jm0607193

35 Purpura M, Lowery RP, Wilson JM, Mannan H, Münch G and Razmovski-Naumovski V: Analysis of different innovative formulations of curcumin for improved relative oral bioavailability in human subjects. Eur J Nutr 57(3): 929-938, 2018. PMID: 28204880. DOI: 10.1007/s00394-016-1376-9

36 Tripodo G, Pasut G, Trapani A, Mero A, Lasorsa FM, Chlapanidas $\mathrm{T}$, Trapani $\mathrm{G}$ and Mandracchia D: Inulin- $\mathrm{d}-\alpha$-tocopherol succinate (INVITE) nanomicelles as a platform for effective intravenous administration of curcumin. Biomacromolecules 16(2): 550-557, 2015. PMID: 15264602. DOI: 10.1021/bm 501616e

37 Thangavel S, Yoshitomi T, Sakharkar MK and Nagasaki Y: Redox nanoparticles inhibit curcumin oxidative degradation and enhance its therapeutic effect on prostate cancer. J Control Release 209: 110-119, 2015. PMID: 25912409. DOI: 10.1016/ j.jconrel.2015.04.025

38 Langone P, Debata PR, Inigo JDR, Dolai S, Mukherjee S, Halat P, Mastroianni K, Curcio GM, Castellanos MR, Raja K and Banerjee P: Coupling to a glioblastoma-directed antibody potentiates antitumor activity of curcumin. Int J Cancer 135(3): 710-719, 2014. PMID: 24142484. DOI: $10.1002 / \mathrm{ijc} .28555$

39 Jamali Z, Hejazi SM, Ebrahimi SM, Moradi-Sardareh H and Paknejad M: Effects of LED-Based photodynamic therapy using red and blue lights, with natural hydrophobic photosensitizers on human glioma cell line. Photodiagnosis Photodyn Ther 21: 5054, 2018. PMID: 29126958. DOI: 10.1016/j.pdpdt.2017. 11.002

40 Singh SP, Sharma M and Gupta PK: Evaluation of phototoxic effects of curcumin loaded in organically modified silica nanoparticles in tumor spheroids of oral cancer cells. Bionanoscience 5(1): 10-21, 2014. PMID: 25511568. DOI: 10.1007/s12668-014-0157-2

41 De Matos RPA, Calmon MF, Amantino CF, Villa LL, Primo FL, Tedesco AC and Rahal P: Effect of curcumin-nanoemulsion associated with photodynamic therapy in cervical carcinoma cell lines. Biomed Res Int 2018: 4057959, 2018. PMID: 29581972. DOI: $10.1155 / 2018 / 4057959$

42 Park K and Lee JH: Photosensitizer effect of curcumin on UVBirradiated $\mathrm{HaCaT}$ cells through activation of caspase pathways. Oncol Rep 17(3): 537-540, 2007. PMID: 17273730. DOI: 10.3892/or.17.3.537

43 Firas Ş, Ruhi MK and Gülsoy M: Photodiagnosis and photodynamic therapy the effect of curcumin in antitumor photodynamic therapy: In vitro experiments with Caco-2 and PC-3 cancer lines. Photodiagnosis Photodyn Ther 27: 95-99, 2019. PMID: 31100447. DOI: 10.1016/j.pdpdt.2019.05.012

44 Muragaki Y, Akimoto J, Maruyama T, Iseki H, Ikuta S, Nitta M, Maebayashi K, Saito T, Okada Y, Kaneko S, Matsumura A, Kuroiwa T, Karasawa K, Nakazato Y and Kayama T: Phase II clinical study on intraoperative photodynamic therapy with talaporfin sodium and semiconductor laser in patients with malignant brain tumors. J Neurosurg 119(4): 845-852, 2013. PMID: 23952800. DOI: 10.3171/2013.7.JNS13415

Received July 9, 2019

Revised August 5, 2019 Accepted August 7, 2019 